\title{
Theoretical Insight into the Spectral Characteristics of Fe(II)-Based Complexes for Dye-Sensitized Solar Cells-Part I: Polypyridyl Ancillary Ligands
}

\author{
Xiaoqing Lu, ${ }^{1}$ Shuxian Wei, ${ }^{2}$ Chi-Man Lawrence Wu, ${ }^{1}$ Ning Ding, ${ }^{1}$ Shaoren Li, ${ }^{2}$ \\ Lianming Zhao, ${ }^{2}$ and Wenyue Guo ${ }^{2}$ \\ ${ }^{1}$ Department of Physics and Materials Science, City University of Hong Kong, Hong Kong \\ ${ }^{2}$ College of Physics Science and Technology, China University of Petroleum, Dongying, Shandong 257061, China
}

Correspondence should be addressed to Chi-Man Lawrence Wu, lawrence.wu@cityu.edu.hk

Received 22 May 2011; Revised 7 July 2011; Accepted 25 July 2011

Academic Editor: Gaetano Di Marco

Copyright (๑) 2011 Xiaoqing Lu et al. This is an open access article distributed under the Creative Commons Attribution License, which permits unrestricted use, distribution, and reproduction in any medium, provided the original work is properly cited.

The design of light-absorbent dyes with cheaper, safer, and more sustainable materials is one of the key issues for the future development of dye-sensitized solar cells (DSSCs). We report herein a theoretical investigation on a series of polypyridyl Fe(II)based complexes of $\mathrm{FeL}_{2}(\mathrm{SCN})_{2},\left[\mathrm{FeL}_{3}\right]^{2+},\left[\mathrm{FeL}^{\prime}(\mathrm{SCN})_{3}\right]^{-},\left[\mathrm{FeL}_{2}^{\prime}\right]^{2+}$, and $\mathrm{FeL}^{\prime \prime}(\mathrm{SCN})_{2}\left(\mathrm{~L}=2,2^{\prime}\right.$-bipyridyl-4,4'-dicarboxylic acid,

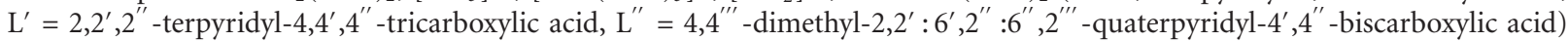
by density functional theory (DFT) and time-dependent DFT (TD-DFT). Molecular geometries, electronic structures, and optical absorption spectra are predicted in both the gas phase and methyl cyanide $(\mathrm{MeCN})$ solution. Our results show that polypyridyl $\mathrm{Fe}(\mathrm{II})$-based complexes display multitransition characters of $\mathrm{Fe} \rightarrow$ polypyridine metal-to-ligand charge transfer and ligand-toligand charge transfer in the range of 350-800 nm. Structural optimizations by choosing different polypyridyl ancillary ligands lead to alterations of the molecular orbital energies, oscillator strength, and spectral response range. Compared with Ru(II) sensitizers, $\mathrm{Fe}(\mathrm{II})$-based complexes show similar characteristics and improving trend of optical absorption spectra along with the introduction of different polypyridyl ancillary ligands.

\section{Introduction}

Due to the features of low cost and high conversion efficiency, dye-sensitized solar cells (DSSCs) based on organic/ inorganic hybrid materials have attracted extensive attention as an alternative to the conventional Si-based solar cells [13]. As crucial light-harvesting elements in DSSCs, the photoexcited sensitizers can inject electrons from their excited states into the semiconductor conduction band, and are recharged by an electrolyte to their initial states [4-6]. Early design of sensitizers had focused on transition metal coordinated complexes because of their unique richness of electronic properties for light absorption as well as photochemical and photophysical behaviors, especially for the photoredox activities [7]. These behaviors were originated from the nature of the coordinated complexes, involving the metal-to-ligand charge transfer (MLCT) character and intervening spin-orbit coupling attached to the presence of metal cations with large atomic numbers [7]. Metal coordinated complexes also facilitate the fine tuning of electronic properties by means of the proper choice of both polypyridyl ancillary ligands and metal cations. Up to now, polypyridyl $\mathrm{Ru}(\mathrm{II})$-based complexes are proven to be the most efficient sensitizers employed in DSSCs. Among them, the tetraprotonated $\mathrm{Ru}\left(4,4^{\prime} \text {-dicarboxy-2,2' -bipyridine }\right)_{2}(\mathrm{NCS})_{2}$ complex (coded as N3) [8] and its doubly protonated analog (coded as N719) [9] exhibit outstanding properties, that is, broad visible light absorption spectrum, high photo-, electro-, thermal and chemical stability, and strong adsorption on the semiconductor surfaces. Using N3 as sensitizers, a solar-toelectric energy conversion efficiency of $10 \%$ was first attained for DSSCs. Therefore, N3 is usually considered as a reference dye for DSSCs and is used as a base for designing other sensitizers. At present, the maximum efficiency of DSSCs is 
12.1\% using $\mathrm{Ru}(\mathrm{II})$-based complex of $\mathrm{C106}$ as a sensitizer [10].

However, considering the high cost and limited availability of Ru, novel dyes using cheaper, safer, and more sustainable metal materials are desirable for next-generation DSSCs. Although Fe and Ru are in the same column of the periodic table, Fe is a first row transition metal and is environmentalfriendly and inexpensive. It is therefore of an interest to determine whether Fe can be used to replace Ru in sensitizers to exhibit similar photophysical and photochemical properties. Recent studies on Fe(II)-based complexes have been reported $[7,11-20]$, in which the geometries and absorption spectra were analyzed. However, better understanding of the electronic structures and spectra characteristics of Fe(II)based complexes for DSSCs is still scarce. In this work, we present a theoretical study on a series of polypyridyl Fe(II)based complexes of $\mathrm{FeL}_{2}(\mathrm{SCN})_{2},\left[\mathrm{FeL}_{3}\right]^{2+},\left[\mathrm{FeL}^{\prime}(\mathrm{SCN})_{3}\right]^{-}$, $\left[\mathrm{FeL}_{2}^{\prime}\right]^{2+}$, and $\mathrm{FeL}^{\prime \prime}(\mathrm{SCN})_{2}\left(\mathrm{~L}=2,2^{\prime}\right.$-bipyridyl-4,4'-dicarboxylic acid, $\mathrm{L}^{\prime}=2,2^{\prime}, 2^{\prime \prime}$-terpyridyl $-4,4^{\prime}, 4^{\prime \prime}$-tricarboxylic acid, $\mathrm{L}^{\prime \prime}=4,4^{\prime \prime \prime}$-dimethyl-2,2 $: 6^{\prime}, 2^{\prime \prime}: 6^{\prime \prime}, 2^{\prime \prime \prime}$-quaterpyridyl$4^{\prime}, 4^{\prime \prime}$-biscarboxylic acid) that follow straightforward design strategies applied to $\mathrm{Ru}(\mathrm{II})$ sensitizers, by means of DFT/TD-DFT calculations. The molecular geometries, electronic structures, and spectral characteristics are elaborated in both the gas phase and MeCN solution.

\section{Computational Methods}

All calculations were performed using the Gaussian 09 program package [21]. The geometrical optimizations for all Fe(II)-based complexes were carried out using the B3LYP exchange correlation functional in conjunction with the pure 6-31G* and mixed DZVP/3-21G* basis sets, in both the gas phase and $\mathrm{MeCN}$ solution. The reason why we chose two basis sets was to eliminate the errors caused by improper selection of basis set. In the pure $6-31 G^{*}$ basis set, all atoms were described in the same basis set. In the mixed DZVP/3$21 \mathrm{G}^{*}$ basis set, the DZVP set [22] supplemented with three sets of uncontracted pure angular momentum $f$ functions was chosen for $\mathrm{Fe}$, and the $3-21 \mathrm{G}^{*}$ basis set for nonmetal atoms. For $\mathrm{Ru}(\mathrm{II})$-based complexes, the B3LYP functional in conjunction with the pure $3-21 \mathrm{G}^{*}$ and mixed SDD/6-31G* basis sets was employed in the geometrical optimizations. The SDD set along with the quasirelativistic MWB (28 core electrons) pseudopotential $[23,24]$ was chosen for $\mathrm{Ru}$ and the $6-31 G^{*}$ basis set for the remaining nonmetal atoms. For simplicity, B3LYP/DZVP was used to stand for the B3LYP functional in conjunction with the mixed DZVP/3$21 \mathrm{G}^{*}$ basis set and B3LYP/SDD for the B3LYP functional in conjunction with the mixed SDD/6-31G* basis set.

TD-DFT calculations were used to investigate the optical properties of the sensitizers. The lowest vertical excitation energy of the system at the ground state geometry can be accurately and efficiently calculated by TD-DFT $[25,26]$. The 70 lowest transitions, up to the energy level of at least $4.50 \mathrm{eV}$, were taken into account in the calculations of the absorption spectra. The solvent effects were evaluated

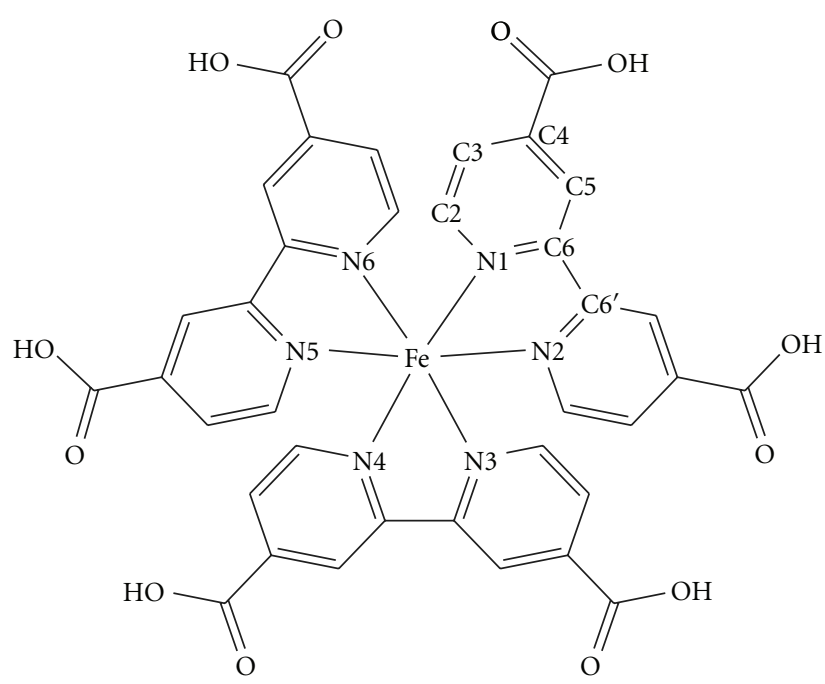

Figure 1: Sketch of chemical structures of the $\left[\mathrm{FeL}_{3}\right]^{2+}$ complex (L $=2,2^{\prime}$-bipyridyl- $4,4^{\prime}$-dicarboxylic acid) with the atom numbering scheme.

using the nonequilibrium implementation of the conductorlike polarizable continuum model (C-PCM) [27-30]. In particular, optimized structures and solvation energies were computed by a cavity model [31] coupled to C-PCM [30]. This approach provides results very close to those obtained by the original dielectric model for high dielectric constant solvents but is significantly more effective in geometry optimizations and less prone to numerical errors arising from the small part of the solute electron cloud lying outside the cavity [30].

\section{Results and Discussion}

In the following sections, we first establish the accuracy for the chosen levels of theory. Then, we present the results of molecular geometries, molecular orbitals and electronic structures, electronic excitations, and absorption spectra of $\mathrm{Fe}$ (II)-based complexes, as well as the comparison with those of $\mathrm{Ru}(\mathrm{II})$-based complexes.

3.1. Calibration. It is essential to calibrate the quality of the geometries obtained at different levels because the accuracy of the calculations of electronic structures used to produce reliable absorption spectra depends highly on the geometrical parameters. However, since there is no optimized complex which corresponds exactly to a experimental result, the closest complex $\left[\mathrm{FeL}_{3}\right]^{2+}\left(\mathrm{L}=2,2^{\prime}\right.$-bipyridyl$4,4^{\prime}$-dicarboxylic acid) is chosen for comparison with the experimental complex, $\left[\mathrm{Fe}(\mathrm{bpy})_{3}\right]^{2+}[11,13]$. Table 1 lists the selected theoretical and experimental parameters of the ground state structures, and the corresponding labeling scheme is given in Figure 1.

The bond length of $\mathrm{Fe}-\mathrm{N}$ in the gas-phase $\left[\mathrm{FeL}_{3}\right]^{2+}$ is $1.997 \AA$ calculated at the B3LYP/6-31G* level and $1.992 \AA$ at the B3LYP/DZVP level (see Table 1), in good agreement with the solid-state distances of $1.965-1.967 \AA[11,13]$. 
TABLE 1: Comparisons between calculated geometrical parameters of the $\left[\mathrm{FeL}_{3}\right]^{2+}$ using B3LYP at different basis sets in the gas phase with experimental values ${ }^{\mathrm{a}}$.

\begin{tabular}{|c|c|c|c|c|c|c|c|}
\hline \multirow{2}{*}{ Parameters } & \multicolumn{5}{|c|}{ B3LYP } & \multicolumn{2}{|c|}{ Expt. } \\
\hline & DZVP & $6-31 G^{*}$ & $\mathrm{TZVP}^{\mathrm{b}}$ & $6-311+\mathrm{G}^{* * b}$ & $\mathrm{DZVP}^{\mathrm{c}}$ & Reference [11] & Reference [13] \\
\hline $\mathrm{R}_{\mathrm{Fe}-\mathrm{N} 1}$ & 1.992 & 1.997 & 2.027 & 2.022 & 2.017 & 1.967 & 1.965 \\
\hline $\mathrm{R}_{\mathrm{N}-\mathrm{C} 2}$ & 1.359 & 1.347 & 1.342 & 1.344 & 1.347 & 1.338 & 1.353 \\
\hline $\mathrm{R}_{\mathrm{N}-\mathrm{C} 6}$ & 1.373 & 1.363 & 1.356 & 1.358 & 1.361 & 1.359 & 1.352 \\
\hline $\mathrm{R}_{\mathrm{C} 2-\mathrm{C} 3}$ & 1.390 & 1.391 & 1.386 & 1.389 & 1.394 & 1.358 & 1.380 \\
\hline $\mathrm{R}_{\mathrm{C} 3-\mathrm{C} 4}$ & 1.395 & 1.396 & 1.389 & 1.391 & 1.396 & 1.380 & 1.377 \\
\hline $\mathrm{R}_{\mathrm{C} 4-\mathrm{C} 5}$ & 1.392 & 1.394 & 1.387 & 1.389 & 1.394 & 1.374 & 1.385 \\
\hline $\mathrm{R}_{\mathrm{C} 5-\mathrm{C} 6}$ & 1.391 & 1.394 & 1.394 & 1.396 & 1.400 & 1.377 & 1.384 \\
\hline $\mathrm{R}_{\mathrm{C} 6-\mathrm{C} 6^{\prime}}$ & 1.466 & 1.472 & 1.473 & 1.475 & 1.478 & 1.471 & 1.473 \\
\hline$\angle \mathrm{N} 1-\mathrm{Fe}-\mathrm{N} 2$ & 81.5 & 81.3 & 80.3 & 80.5 & 80.8 & 81.8 & 81.5 \\
\hline$\angle \mathrm{N} 1-\mathrm{Fe}-\mathrm{N} 3$ & 88.4 & 88.2 & & & 88.7 & & 90.7 \\
\hline$\angle \mathrm{N} 1-\mathrm{Fe}-\mathrm{N} 5$ & 95.1 & 95.3 & & & 95.4 & & 94.1 \\
\hline
\end{tabular}

${ }^{a}$ Bond lengths are in angstroms and angles are in degrees.

${ }^{\mathrm{b}}$ Results from [13].

${ }^{\mathrm{c}}$ Results from [19].

The bond lengths of $\mathrm{C}-\mathrm{N}$ and $\mathrm{C}-\mathrm{C}$ in the $\mathrm{N} 1$ containing pyridine ring are in the range of $1.347-1.373 \AA$ and $1.390-$ $1.396 \AA$, compared to the experimental values of 1.338 $1.359 \AA$ and $1.358-1.385 \AA$, respectively. The bite-angles of the bpy-domains, $\angle \mathrm{N} 1-\mathrm{Fe}-\mathrm{N} 2$, is $81.3^{\circ}$ obtained at the B3LYP/6-31G* level and $81.5^{\circ}$ at the B3LYP/DZVP level, very close to the experimental values of $81.5-81.8^{\circ}[11,13]$. Moreover, a maximum skewing of $2.5^{\circ}$ of the calculated interbpy angles $(\angle \mathrm{N} 1-\mathrm{Fe}-\mathrm{N} 3$ and $\angle \mathrm{N} 1-\mathrm{Fe}-\mathrm{N} 5)$ is in good agreement with the available experimental data. In addition, previous calculations using the B3LYP functional with pure DZVP [19], TZVP [13], and 6-311 + $\mathrm{G}^{* *}[13]$ basis sets are also listed in Table 1 for comparison. The deviations are less than 3\% between our results and the experimental and previous calculated values. Considering that our study is performed in the gas phase and does not account for the packing and counter-ion effects that are present in the solid state, our calculated geometries match excellently with experimental results. The good agreements demonstrate the reliability of the chosen model and level of theory.

Considering that TD-DFT excitation energies are dependent on the DFT functionals, benchmark calculations of the absorption spectra using the CAM-B3LYP functional are also provided for $\mathrm{Fe}$ (II)-based complex of $\mathbf{1}$ in both the gas phase and $\mathrm{MeCN}$ solution. Seen from Figure S1 (in Supplementary Material available online at doi: $10.1155 / 2011 / 316952)$, these two DFT functionals indeed give consistent absorption spectra. These results justify the reliability of our model and levels of theory. In addition, benchmark calculations containing diffusion functions (e.g., 6-31+ $\mathrm{G}^{*}$ ) were performed, and the results were very similar to those without the diffusion functions. This is in good agreement with our previous studies on $\mathrm{Ru}(\mathrm{II})$-based complexes [24]. Because the results of $\mathrm{Fe}(\mathrm{II})$-based complexes calculated at the B3LYP/6-31G* and B3LYP/DZVP levels are very close to each other, only the B3LYP/6-31G* results will be used for clarification, unless otherwise stated. In the case of $\mathrm{Ru}(\mathrm{II})$-based complexes, the
B3LYP/SDD results will be chosen to compare with Fe(II)based complexes.

3.2. Molecular Geometries. The optimized molecular structures of the polypyridyl $\mathrm{Fe}(\mathrm{II})$-based complexes of $\mathrm{FeL}_{2}(\mathrm{SCN})_{2}, \quad\left[\mathrm{FeL}_{3}\right]^{2+}, \quad\left[\mathrm{FeL}^{\prime}(\mathrm{SCN})_{3}\right]^{-}, \quad\left[\mathrm{FeL}_{2}^{\prime}\right]^{2+}$, and $\mathrm{FeL}^{\prime \prime}(\mathrm{SCN})_{2}$ are shown in Figure 2, together with the atom numbering scheme. Table 2 summarizes the selected geometrical parameters of the fully optimized $\mathrm{Fe}(\mathrm{II})$-based complexes at the B3LYP/6-31G* level and N3 at the B3LYP/DZVP level in MeCN solution.

Fe coordination complexes in its Fe(II) form have septet ground state with $\mathrm{d}^{5} \mathrm{~s}^{1}$ configuration, which allows it to bind to six neighboring nitrogen ions to form octahedral complexes. The geometry of $\mathbf{1}$ with a cis arrangement of the thiocyanate is optimized to be a pseudooctahedral $C_{2}$ symmetry, while the geometry of the trans isomer $\mathbf{1}^{\prime}$ exhibits an almost $\mathrm{D}_{2}$ symmetry, as shown in Figure 2. For $\mathbf{1}$ and $\mathbf{1}^{\prime}$, the bond lengths of $\mathrm{Fe}-\mathrm{N}$ (thiocyanate) are calculated to be almost the same, while the $\mathrm{Fe}-\mathrm{N}$ (bpy) bond lengths are $\sim 1.98 \AA$ and $\sim 2.02 \AA$, respectively. The bite angles of the bpydomains $(\angle \mathrm{N} 1-\mathrm{Fe}-\mathrm{N} 2$ and $\angle \mathrm{N} 3-\mathrm{Fe}-\mathrm{N} 4)$ show a deviation of $1.2^{\circ}$ between these two isomers (see Table 2). These differences of both bond lengths and angles correspond to the difference that the trans isomer $\mathbf{1}^{\prime}$ is $12.90 \mathrm{kcal} \mathrm{mol}^{-1}$ higher in the binding energy than the corresponding cis isomer 1 . To evaluate the protonation/deprotonation effect as appearing between $\mathrm{N} 3$ and its analog $\mathrm{N} 719$, the $\mathrm{H}^{+}$cations on carboxylic groups are substituted by methyl $(\mathbf{1} \rightarrow \mathbf{2})$. This substitution has slight effect on the geometries, especially for the skeleton parameters (see Table 2). Thiocyanate ligands are usually chosen as the electron-donating groups in the most efficient $\mathrm{Ru}(\mathrm{II})$-based sensitizers. However, from a chemical point of view, the thiocyanate seems to be the weakest part [6]. This situation can be improved by substituting thiocyanate in $\mathbf{1}$ with a dcbpy ligand $(\mathbf{1} \rightarrow \mathbf{3})$. 


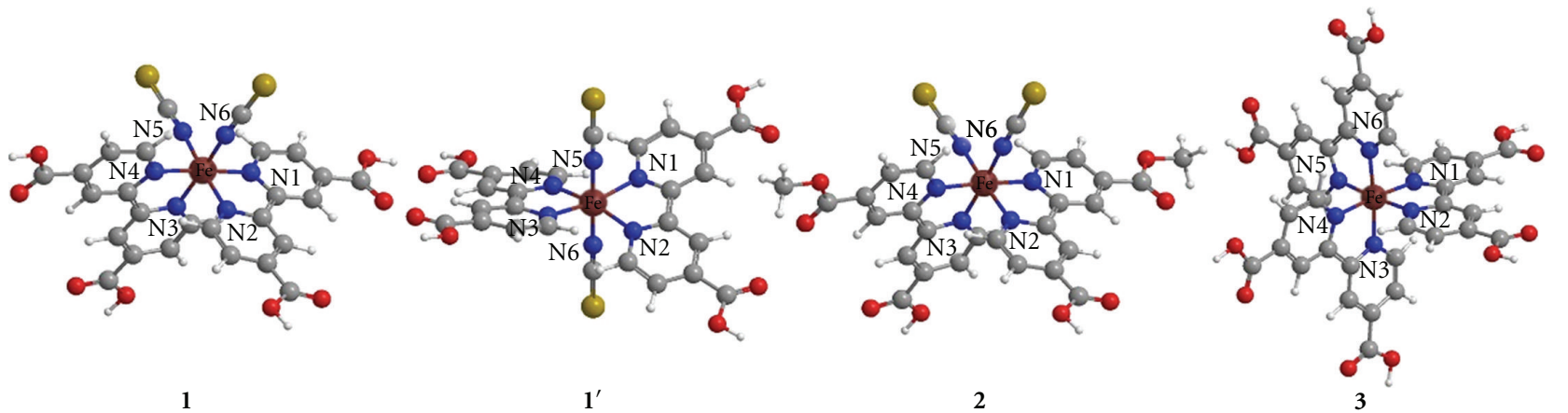

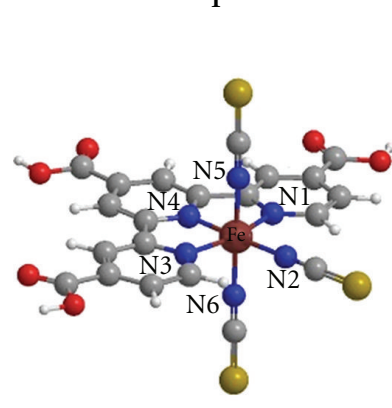

4

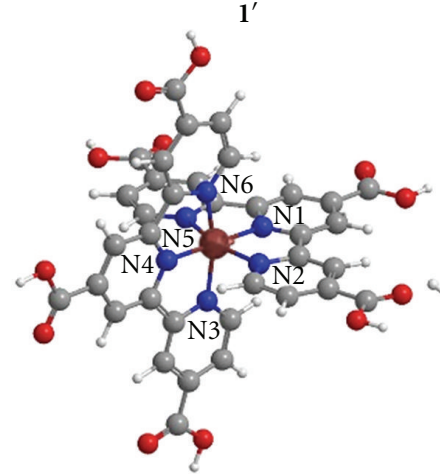

5

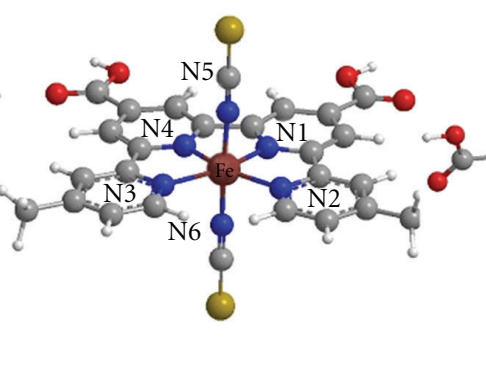

6

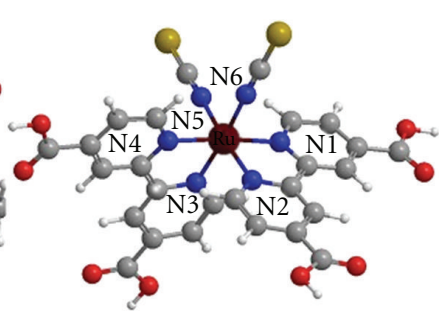

N3

FIgURE 2: Optimized structures of polypyridyl Fe(II)-based complexes and N3 with the atom numbering scheme.

TABLE 2: Selected geometrical parameters of the polypyridyl Fe(II)-based complexes calculated at the B3LYP/6-31G* level in MeCN solution and $\mathrm{N} 3$ calculated at the B3LYP/SDD level in MeCN solution ${ }^{\mathrm{a}, \mathrm{b}}$.

\begin{tabular}{lcccccccc}
\hline Parameters & $\mathbf{1}$ & $\mathbf{1}^{\prime}$ & $\mathbf{2}$ & $\mathbf{3}$ & $\mathbf{4}$ & $\mathbf{5}$ & $\mathbf{6}$ \\
\hline $\mathrm{R}_{\mathrm{M}-\mathrm{N} 1}$ & 1.981 & 2.018 & 1.984 & 1.992 & 1.990 & 1.897 & 1.881 & 2.083 \\
$\mathrm{R}_{\mathrm{M}-\mathrm{N} 2}$ & 1.979 & 2.018 & 1.981 & 1.991 & 1.954 & 2.000 & 2.062 \\
$\mathrm{R}_{\mathrm{M}-\mathrm{N} 3}$ & 1.979 & 2.019 & 1.981 & 1.991 & 1.991 & 1.999 & 2.063 \\
$\mathrm{R}_{\mathrm{M}-\mathrm{N} 4}$ & 1.980 & 2.019 & 1.984 & 1.992 & 1.877 & 1.897 & 1.880 & 2.076 \\
$\mathrm{R}_{\mathrm{M}-\mathrm{N} 5}$ & 1.945 & 1.945 & 1.947 & 1.992 & 1.946 & 1.999 & 1.933 \\
$\mathrm{R}_{\mathrm{M}-\mathrm{N} 6}$ & 1.945 & 1.944 & 1.947 & 1.991 & 1.947 & 2.000 & 1.933 \\
$\angle \mathrm{N} 1-\mathrm{M}-\mathrm{N} 2$ & 81.5 & 80.3 & 81.5 & 81.3 & 98.3 & 81.0 & 80.5 & 2.063 \\
$\angle \mathrm{N} 2-\mathrm{M}-\mathrm{N} 3$ & 91.0 & 101.6 & 90.9 & 88.2 & 98.3 & 91.4 & 116.8 & 78.6 \\
$\angle \mathrm{N} 3-\mathrm{M}-\mathrm{N} 4$ & 81.5 & 80.3 & 81.5 & 81.4 & 81.7 & 81.0 & 80.5 & 78.6 \\
$\angle \mathrm{N} 5-\mathrm{M}-\mathrm{N} 6$ & 91.0 & 179.9 & 90.8 & 81.3 & 178.6 & 91.4 & 173.4 & 90.1 \\
$\angle \mathrm{N} 1-\mathrm{N} 2-\mathrm{N} 3-\mathrm{N} 4$ & -111.2 & 22.8 & -111.4 & -110.8 & -0.1 & -106.0 & 0.1 & -112.6 \\
\hline
\end{tabular}

${ }^{a}$ Bond lengths are in angstroms, and angles are in degrees.

${ }^{\mathrm{b}} \mathrm{M}$ presents $\mathrm{Fe}$ in Fe(II)-based complexes and Ru in N3.

The interbpy angle in 3 is distorted somewhat, as indicated by the alteration of $\angle \mathrm{N} 2-\mathrm{Fe}-\mathrm{N} 3\left(2.8^{\circ}\right)$. Relatively, distortions are very small for both bond lengths and bite angles of $\mathbf{3}$ with respect to those of $\mathbf{1}$.

The optimized geometry of $\mathbf{4}$ shows almost a $\mathrm{C}_{s}$ symmetric arrangement of the ligands, and the octahedral dispositions of the $\mathrm{N}$ atoms around the $\mathrm{Fe}$ center are distorted due to the different nature of thiocyanate and tricarboxylic terpyridine (tctpy) ligands. The difference in bond lengths of Fe-N (thiocyanate: 1.946-1.954 $\AA$ ) and $\mathrm{Fe}-$ N (bpy: 1.877-1.991 $\AA$ ) confirms this point (see Table 2). However, the dihedral angle of $\angle \mathrm{N} 1-\mathrm{N} 2-\mathrm{N} 3-\mathrm{N} 4\left(-0.1^{\circ}\right)$ mirrors the fact that the involved $\mathrm{N}$ atoms are almost in the same plane, quite different from that of the trans isomer $\mathbf{1}^{\prime}\left(22.8^{\circ}\right)$. Substituting tctpy for thiocyanates makes the complex 5 a $\mathrm{C}_{2}$ symmetry, in which the geometrical parameters including the bond lengths and angles related to two tctpy ligands are exactly the same with each other.

For the dicarboxylic quaterpyridine (dcqpy) containing $\mathrm{Fe}$ (II)-based complex, 6, the Fe-N (dcqpy) bond lengths are in the range of $1.880-2.063 \AA$ calculated at the $6-31 G^{*}$ level in MeCN solution. A comparison of the optimized parameters shows that complex $\mathbf{6}$ has shorter Fe-N (thiocyanate) distances with respect to that in $\mathbf{1}^{\prime}$ (1.933 versus 1.944-1.945 $\AA$ ). This may result from the weaker interaction between $\mathrm{Fe}$ and a tetradentate ligand with respect to that 


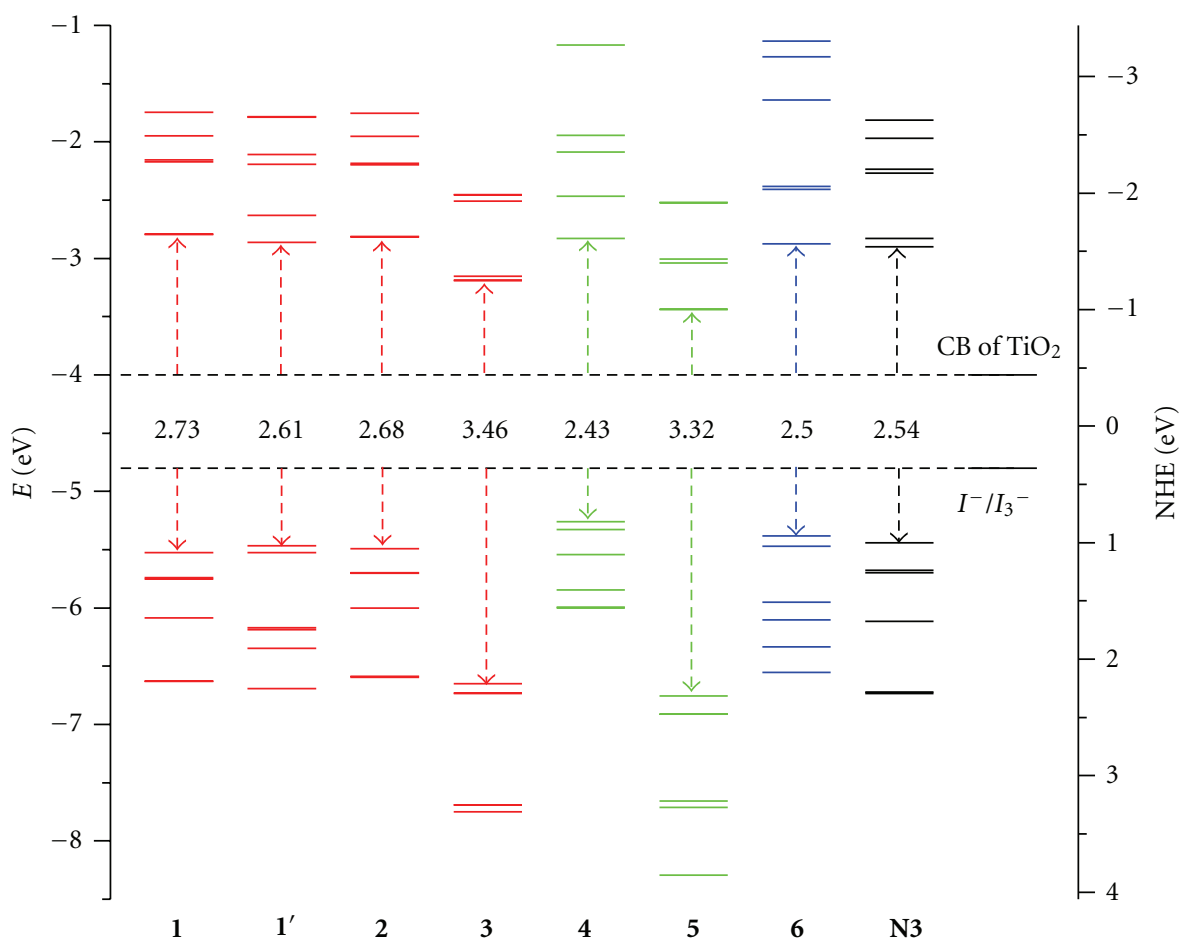

Figure 3: Energy levels and HOMO-LUMO gaps of Fe(II)-based complexes calculated at the B3LYP/6-31G* level in MeCN solution.

between Fe and two bidentate ligands, and thus the stronger interaction between $\mathrm{Fe}$ and thiocyanate ligands shortens the Fe-N (thiocyanate) distances. Similar phenomena also appear for the $\mathrm{Ru}(\mathrm{II})$-based complexes when comparing dcqpy containing complex N886 with dcbpy containing complex N3 [32].

3.3. Molecular Orbitals and Electronic Structures. Since the crucial electronic excitations occur from the highest occupied molecular orbitals (HOMOs) to the lowest unoccupied molecular orbitals (LUMOs), it is therefore important to form efficient charge-separated states with the HOMOs localized on the donor subunit and the LUMOs on the acceptor subunit. The molecular orbital energy levels and the HOMO-LUMO gaps of Fe(II)-based complexes are depicted in Figure 3. In view of the distributions of frontier orbital energies, similar molecular orbital shapes would be envisaged for the complexes with the same ancillary ligand. Therefore, 1, 4, and $\mathbf{6}$ are chosen to exhibit the electron distributions of the frontier molecular orbitals, as shown in Figure 4.

For 1 in MeCN solution, the three highest HOMOs (from HOMO to $\mathrm{HOMO}-2$ ) are a set of quasi degenerate orbitals, originating from the combination of $\mathrm{Fe}_{2 g}$ orbitals $\left(\mathrm{d}_{x y}, \mathrm{~d}_{x z}\right.$, and $\left.\mathrm{d}_{y z}\right)$ with the $2 \mathrm{p}$ orbital and lone pairs of the thiocyanate ligands. The following $\mathrm{HOMO}-3$ shows similar orbital compositions from thiocyanate ligands but without the contributions from the Fe $t_{2 g}$ orbitals with respect to the first three HOMOs (see Figure 4(a)). Compared with those in N3 [33], the first four HOMOs in Fe(II)-based complexes 1 show very close orbital compositions and percentages. Not only that, Fe also shows similar field splitting in $\mathbf{1}$ to that of $\mathrm{Ru}$ in N3, mirrored by the molecular orbital energy levels of HOMOs shown in Figure 3. The four lowest LUMOs (from LUMO to LUMO+3) of 1, lying at least $2.73 \mathrm{eV}$ about the $\mathrm{HOMO}$ in the range of $0.64 \mathrm{eV}$, result mainly from the $\pi^{*}$ combinations of the $\mathrm{C}$ and $\mathrm{N}$ atoms localized on the dcbpy ligands (see Figure 4(a)). Since the carboxylic group of the dcbpy ligands has a strong electron-withdrawing ability, the LUMOs are mainly localized on the dcbpy ligands. The anchoring groups involved in those LUMOs would facilitate the electron injection from the excited state of the sensitizers into the semiconductor. Here, it would be specially mentioned that six HOMOs and LUMOs are presented but less levels are observed in Figure 3 due to the degeneracy. For instance, HOMO-1, HOMO-4, LUMO, and LUMO+2 of 1 correspond to $\mathrm{HOMO}-2, \mathrm{HOMO}-5, \mathrm{LUMO}+1$, and $\mathrm{LUMO}+3$ in energies; thus only eight levels can be observed in Figure 3. In fact, this situation also appears in all the other $\mathrm{Fe}(\mathrm{II})$-based complexes (see Figure 3).

It can be seen from Figure 3 that the energy levels of $\mathbf{2}$ are very close to those of $\mathbf{1}$, indicating that the protonated/deprotonation effect is slight for $\mathrm{Fe}(\mathrm{II})$-based complexes in MeCN solution. However, the isomerization effect has larger influence on the frontier molecular orbitals, mirrored by the alteration of both the energy levels and energy gap. The most obvious alteration between $\mathbf{1}$ and $\mathbf{1}^{\prime}$ is the degenerate orbitals of HOMOs. The first set for $\mathbf{1}$ is composed of the three highest HOMOs (from HOMO to HOMO-2) in the range of $0.22 \mathrm{eV}$, while that for $\mathbf{1}^{\prime}$ is composed of the two highest HOMOs in the range of $0.06 \mathrm{eV}$. This points out the difference of the field splitting of $\mathrm{Fe}$ 


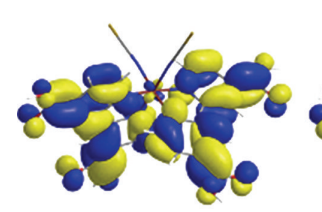

$\mathrm{LUMO}+3$

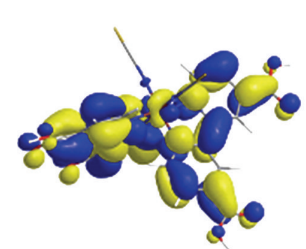

LUMO

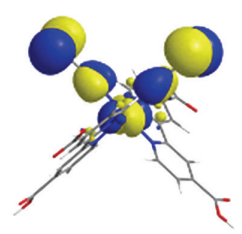

HOMO-2

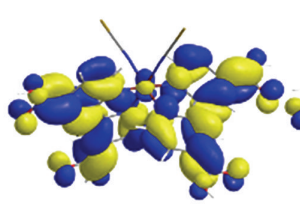

$\mathrm{LUMO}+2$

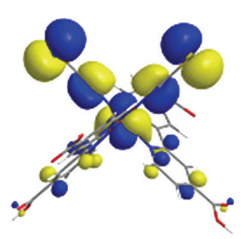

HOMO

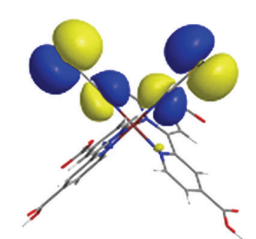

HOMO-3

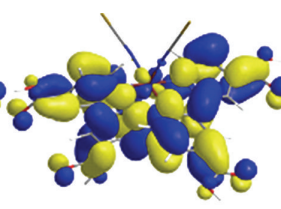

LUMO+1

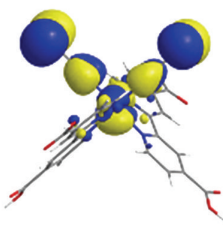

HOMO-1

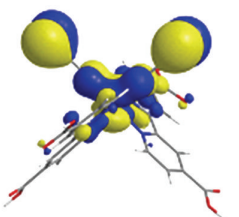

HOMO-4

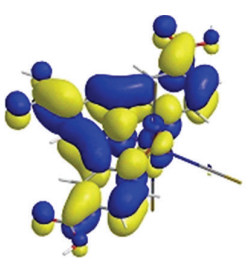

LUMO

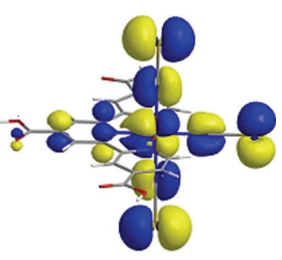

HOMO

(b)
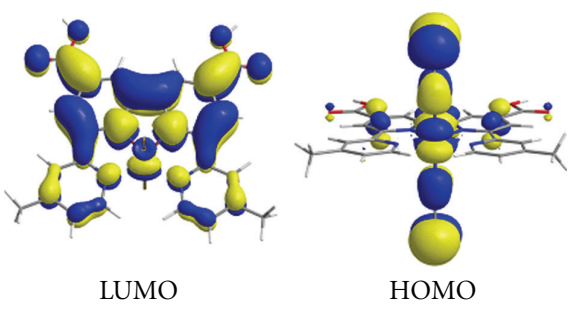

(c)

FIGURE 4: Selected frontier molecular orbitals of the complexes 1 (a), 4 (b), and 6 (c) calculated at the B3LYP/6-31G* level in MeCN solution. Isodensity contour: 0.02 .

between $\mathbf{1}^{\prime}$ and $\mathbf{1}$. Due to the alteration of orbital levels, the HOMO-LUMO gap of $\mathbf{1}^{\prime}$ reduces to $2.61 \mathrm{eV}$ with respect to $2.73 \mathrm{eV}$ in $\mathbf{1}$. Substitution of the thiocyanates in $\mathbf{1}$ with a dcbpy ligand $(\mathbf{1} \rightarrow \mathbf{3})$ has great influence on the energy levels and the HOMO-LUMO gap, as shown in Figure 3. All the molecular orbital energies of $\mathbf{3}$ are downshifted but the HOMOs are stabilized much more than the LUMOs. Accordingly, the HOMO-LUMO gap of 3 is increased to $3.46 \mathrm{eV}$.

For 4 in MeCN solution, the HOMO shows mainly contributions from the combination of Fe center and three thiocyanate ligands, while the LUMO shows contributions from the tctpy ligand, as shown in Figure 4(b). Compared with $\mathbf{1}$, the six highest HOMOs of $\mathbf{4}$ are unshifted and lie in a smaller range of $0.74 \mathrm{eV}$, while the LUMO is close to that of 1 but the six lowest LUMOs lie in a larger range of $2.84 \mathrm{eV}$. Accordingly, the HOMO-LUMO gap of 4 is calculated to be $2.43 \mathrm{eV}$. The smaller HOMO-LUMO gap would help decrease the excitation energy, and this is beneficial for the absorption spectrum to shift towards the longer wavelength of the visible region. Substitution of the thiocyanates in $\mathbf{4}$ with a tctpy ligand $(\mathbf{4} \rightarrow \mathbf{5})$ shows the same trend on the energy levels as $\mathbf{1} \rightarrow \mathbf{3}$ substitution. As seen from Figure 3, both the HOMO and LUMO levels of $\mathbf{5}$ are lower than those of $\mathbf{4}$, and the HOMO-LUMO gap of $\mathbf{5}$ is $0.89 \mathrm{eV}$ smaller than that of 4. Obviously, both the energy levels and HOMOLUMO gaps of the thiocyanate-substituted complexes ( 3 and 5) are less favorable than those unsubstituted complexes (1 and 4) with respect to the reference dye N3.
For 6 in MeCN solution, the HOMO also shows main contributions from the combination of Fe center orbital and two thiocyanate ligands, while the LUMO shows contributions from the dcqpy ligand, as shown in Figure 4(c). Fe shows slightly different field splitting in $\mathbf{6}$ compared with that in $\mathbf{1}$, which leads to slightly different energy levels of the HOMOs, as shown in Figure 3. The great difference in energy levels of LUMOs between $\mathbf{1}$ and $\mathbf{6}$ correspond to the great structural difference in the polypyridyl ancillary ligands of dcbpy and dcqpy. The HOMO-LUMO gap of 6 is calculated to be $2.50 \mathrm{eV}$.

3.4. Electronic Excitations and Absorption Spectra. Figure 5 presents the simulated absorption spectra of $\mathrm{Fe}(\mathrm{II})$-based complexes at the B3LYP/6-31G* level and N3 at the B3LYP/SDD level in MeCN solution. Table 3 lists excitation energies, oscillator strengths, and relative orbital contributions of the optical transitions between 350 and $800 \mathrm{~nm}$ for 1,4 , and 6 , in which only oscillator strengths larger than 0.01 and orbital percentages larger than $10 \%$ are presented. The gas phase absorption spectra and transitions information of $\mathbf{1}^{\prime}, 2,3$, and $\mathbf{5}$ are provided in Figure S2 and Table S1, respectively. As seen from Figure S2, the band shapes of spectra obtained in the gas phase are qualitatively similar to those in $\mathrm{MeCN}$ solution, but the oscillator strengths are stronger for most spectra in $\mathrm{MeCN}$ solution at the longer wavelength range. In order to depict the real environmental, the results obtained in $\mathrm{MeCN}$ solution will be used for analysis. 
TABLe 3: Selected excitation energies (E, nm), oscillator strength $(f)$, and relative orbital contributions of the absorption spectra of Fe(II)based complexes calculated at the B3LYP/6-31G* level in MeCN solution.

\begin{tabular}{|c|c|c|c|}
\hline$E$ & $f$ & & Compositions \\
\hline \multicolumn{4}{|c|}{1} \\
\hline 633.5 & 0.022 & & $\mathrm{H}-0 \rightarrow \mathrm{L}+1(87 \%)$ \\
\hline 594.4 & 0.029 & & $\mathrm{H}-1 \rightarrow \mathrm{L}+0(76 \%)$ \\
\hline 559.4 & 0.054 & & $\mathrm{H}-2 \rightarrow \mathrm{L}+1(84 \%)$ \\
\hline 445.3 & 0.060 & & $\mathrm{H}-3 \rightarrow \mathrm{L}+0(55 \%) \mathrm{H}-0 \rightarrow \mathrm{L}+3(41 \%)$ \\
\hline 442.9 & 0.033 & & $\mathrm{H}-3 \rightarrow \mathrm{L}+1(66 \%) \mathrm{H}-0 \rightarrow \mathrm{L}+2(23 \%)$ \\
\hline 431.1 & 0.023 & & $\mathrm{H}-1 \rightarrow \mathrm{L}+2(82 \%)$ \\
\hline 415.6 & 0.022 & & $\mathrm{H}-2 \rightarrow \mathrm{L}+3(95 \%)$ \\
\hline 395.1 & 0.070 & & $\mathrm{H}-4 \rightarrow \mathrm{L}+0(61 \%)$ \\
\hline 361.2 & 0.032 & & $\mathrm{H}-3 \rightarrow \mathrm{L}+2(33 \%) \mathrm{H}-6 \rightarrow \mathrm{L}+1(21 \%)$ \\
\hline \multicolumn{4}{|r|}{ 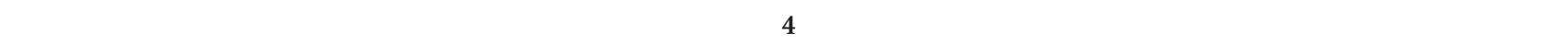 } \\
\hline 766.8 & 0.017 & & $\mathrm{H}-1 \rightarrow \mathrm{L}+0(93 \%)$ \\
\hline 693.0 & 0.026 & & $\mathrm{H}-0 \rightarrow \mathrm{L}+0(87 \%) \mathrm{H}-1 \rightarrow \mathrm{L}+1(11 \%)$ \\
\hline 609.4 & 0.031 & & $\mathrm{H}-0 \rightarrow \mathrm{L}+1(96 \%)$ \\
\hline 473.4 & 0.064 & & $\mathrm{H}-0 \rightarrow \mathrm{L}+2(84 \%)$ \\
\hline 471.1 & 0.054 & & $\mathrm{H}-1 \rightarrow \mathrm{L}+2(92 \%)$ \\
\hline 422.5 & 0.016 & & $\mathrm{H}-6 \rightarrow \mathrm{L}+0(86 \%)$ \\
\hline \multicolumn{4}{|c|}{6} \\
\hline 724.5 & 0.014 & & $\mathrm{H}-1 \rightarrow \mathrm{L}+0(93 \%)$ \\
\hline 682.4 & 0.018 & & $\mathrm{H}-0 \rightarrow \mathrm{L}+0(85 \%)$ \\
\hline 561.5 & 0.048 & & $\mathrm{H}-0 \rightarrow \mathrm{L}+1(90 \%)$ \\
\hline 507.0 & 0.020 & & $\mathrm{H}-4 \rightarrow \mathrm{L}+8(34 \%) \mathrm{H}-2 \rightarrow \mathrm{L}+8(34 \%) \mathrm{H}-1 \rightarrow \mathrm{L}+2(26 \%)$ \\
\hline 493.4 & 0.018 & & $\mathrm{H}-1 \rightarrow \mathrm{L}+1(64 \%) \mathrm{H}-0 \rightarrow \mathrm{L}+0(12 \%)$ \\
\hline 396.2 & 0.023 & & $\mathrm{H}-0 \rightarrow \mathrm{L}+3(96 \%)$ \\
\hline 350.1 & 0.024 & & $\mathrm{H}-7 \rightarrow \mathrm{L}+0(28 \%) \mathrm{H}-0 \rightarrow \mathrm{L}+5(25 \%) \mathrm{H}-1 \rightarrow \mathrm{L}+4(22 \%)$ \\
\hline
\end{tabular}

anly oscillator strength $f>0.01$ and orbital percentage $>10 \%$ are reported, where $\mathrm{H}$ stand for HOMO and L for LUMO.

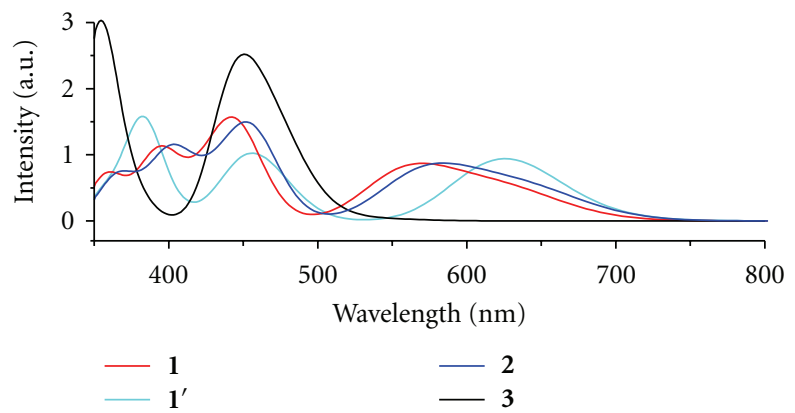

(a)

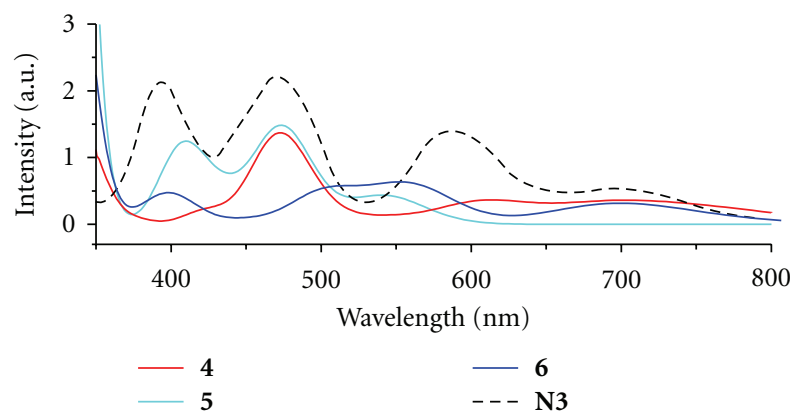

(b)

FIgure 5: Simulated absorption spectra of Fe(II)-based complexes (solid lines) at the B3LYP/6-31G* level and N3 (dash line) at the B3LYP/SDD level in MeCN solution.

In the energy range investigated, there are four bands that clearly appear with the intensity maxima centered at $\sim 362, \sim 395, \sim 442$, and $\sim 571 \mathrm{~nm}$ for 1 (see Figure 5). At $\sim 362 \mathrm{~nm}$, the band originates from the starting orbitals of HOMO-3/HOMO- 6 combination to the arriving orbitals of $\mathrm{LUMO}+1 / \mathrm{LUMO}+2$ with the oscillator strength of 0.032 . As seen from Figure $4(\mathrm{a})$, the $\mathrm{HOMO}-3 \rightarrow \mathrm{LUMO}+2$ transition shows the interligand $\pi \rightarrow \pi^{*}$ transition from the thiocyanate ligands to the dcbpy ligands, a typical LLCT character. At $\sim 395 \mathrm{~nm}$, the HOMO $-4 \rightarrow$ LUMO (61\%) transition shows the strongest oscillator strength of 0.070 involving the $\mathrm{Fe}(\mathrm{II})$ center to the dcbpy ligand and interligand $\pi \rightarrow \pi^{*}$ transitions, a multitransition character of MLCT and LLCT. As shown in Table 3, the band at $442 \mathrm{~nm}$ of 1 is composed of a series of peaks from $415.6 \mathrm{~nm}$ to $445.3 \mathrm{~nm}$. Among them, the peak at $445.3 \mathrm{~nm}$ includes 
the transitions of HOMO/HOMO-3 as the starting orbitals and LUMO/LUMO+3 as the arriving orbitals, exhibiting a multitransition character of LLCT and MLCT. At $\sim 571 \mathrm{~nm}$, a broad absorption band is observed with the peaks ranging from $559.4 \mathrm{~nm}$ to $633.5 \mathrm{~nm}$. The first vertical excitation occurs at $633.5 \mathrm{~nm}(f=0.022)$, originated from the HOMO $\rightarrow$ LUMO+1 (87\%) transition with the multitransition character of MLCT and LLCT.

As shown in Figure 5, the calculated absorption spectrum of the derivative $\mathbf{2}$ is quantitatively similar to that of $\mathbf{1}$ but with a slight blueshift. This corresponds to the minor alterations of the energy levels caused by the slight structural changes. It can also be confirmed by comparing the excitations of $\mathbf{2}$ with those of $\mathbf{1}$ in Tables S1 and 3. The absorption spectrum of isomer $\mathbf{1}^{\prime}$ is quite different from that of $\mathbf{1}$ due to the great difference in geometry. As seen from Figure 5, three bands are found to center at $\sim 382, \sim 457$, and $\sim 625 \mathrm{~nm}$ for $\mathbf{1}^{\prime}$ in the energy range investigated. The bands at $\sim 625 \mathrm{~nm}$ are composed of two peaks, involving the HOMO $-1 \rightarrow$ LUMO transition $(f=0.063)$ at $630.8 \mathrm{~nm}$ and the combinations of $\mathrm{HOMO} / \mathrm{HOMO}-1 \rightarrow$ LUMO/LUMO +9 transition $(f=$ 0.024 ) at $603.6 \mathrm{~nm}$ (see Table S1). The oscillator strength of the first vertical excitation of $\mathbf{1}^{\prime}$ is stronger than that of $\mathbf{1}$, but the band of $\mathbf{1}^{\prime}$ at the longer wavelength region is not as broad as that of $\mathbf{1}$. Substitution of the thiocyanates with a dcbpy ligand $(\mathbf{1} \rightarrow \mathbf{3})$ shrinks the effective spectral response range sharply, corresponding to the enlarged HOMO-LUMO gaps. Only one band is observed at $\sim 450 \mathrm{~nm}$ in the energy range investigated, originated from the combinations of $\mathrm{HOMO}-1 / \mathrm{HOMO}-2 \rightarrow$ LUMO +2 transitions. Compared with $\mathrm{Ru}(\mathrm{II})$-based complex N3, the absorption spectra of $\mathbf{1}$ and its derivative 2 have similar band shape. However, the bands in the range of $400-600 \mathrm{~nm}$ are only two-thirds as much oscillator strength as those of N3.

For 4 in $\mathrm{MeCN}$ solution, the calculated absorption spectrum is shifted towards the near-infrared region, which can be comparable with the region that the black dye can reach [34].Three bands are observed with the intensity maxima centered at $\sim 472, \sim 609$, and $\sim 704 \mathrm{~nm}$ in the energy range investigated (see Figure 5). At $\sim 472 \mathrm{~nm}$, the bands are composed of two peaks, originated from HOMO-1 $\rightarrow$ LUMO+2 (92\%) transition at $471.1 \mathrm{~nm}$ and HOMO $\rightarrow$ LUMO+2 (84\%) transition at $473.4 \mathrm{~nm}$. The oscillator strengths reach 0.054 and 0.064 , respectively. An analysis of both transitions shows the multitransition character of MLCT and LLCT involving the Fe center to the tctpy ligand and interligand $\pi \rightarrow \pi^{*}$ transitions. At $\sim 609 \mathrm{~nm}$, the $\mathrm{HOMO} \rightarrow \mathrm{LUMO}+1(96 \%)$ transition has the oscillator strength of 0.031 , exhibiting a multitransition character of MLCT and LLCT. The band at $\sim 704 \mathrm{~nm}$ is composed of two peaks at 693.0 and $766.8 \mathrm{~nm}$. The peak at $766.8 \mathrm{~nm}$ corresponds to the first vertical excitation, originated from the HOMO-1 $\rightarrow$ LUMO transition with the oscillator strength of 0.017 . This extension towards the longer wavelength region would be greatly beneficial for the sensitizers to absorb the low-energy photons and thus improves the DSSCs spectral response range. The substitution of the thiocyanates with a tctpy ligand $(\mathbf{4} \rightarrow \mathbf{5})$ renders the absorption spectrum of 5 to be redshifted sharply, similar to the effect of substitution of the thiocyanates with a dcbpy ligand $(\mathbf{1} \rightarrow$ 3 ). The longest wavelength region of the bands for $\mathbf{5}$ is at $\sim 543 \mathrm{~nm}$, composed of two peaks from the transitions of $\mathrm{HOMO} \rightarrow$ LUMO and $\mathrm{HOMO} \rightarrow \mathrm{LUMO}+1$.

For 6 in the energy range investigated, three separated absorption bands are found to center at $\sim 396, \sim 552$, and $\sim 699 \mathrm{~nm}$ (see Figure 5). At $\sim 396 \mathrm{~nm}$, the band is composed of the transition of HOMO $\rightarrow$ LUMO $+3(f=0.023)$. At $\sim 552 \mathrm{~nm}$, the band is mainly composed of transitions in the range of $493.4-561.5 \mathrm{~nm}$, originated from the starting orbitals of the $\mathrm{HOMO} / \mathrm{HOMO}+1 / \mathrm{HOMO}+2 / \mathrm{HOMO}+4$ combinations to the arriving orbitals of LUMO/LUMO + 1/LUMO+2/LUMO+8 (see Table 3). An analysis of these transition shows that excitations correspond to electron transfer from the $\mathrm{Fe} 3 \mathrm{~d}$ orbitals to the unoccupied $\pi^{*}$ orbitals of the dcqpy ligand and from the occupied orbitals of the thiocyanate ligands to the unoccupied $\pi^{*}$ orbitals of the dcqpy ligand, that is, a mixture of MLCT and LLCT transitions. At $\sim 699 \mathrm{~nm}$, the band is mainly composed of the transitions of HOMO $\rightarrow$ LUMO $(85 \%)$ at $682.4 \mathrm{~nm}$ $(f=0.018)$ and HOMO-1 $\rightarrow$ LUMO $(93 \%)$ at $724.5 \mathrm{~nm}$ $(f=0.014)$, showing primary MLCT and LLCT characters (see Figure 4(c)). Compared with $\mathbf{1}$, the absorption spectrum of dcqpy containing complex $\mathbf{6}$ is blueshifted towards the longer wavelength range, similar to the phenomenon that occurs for $\mathrm{Ru}(\mathrm{II})$-based sensitizers when going from $\mathrm{N} 3$ to dcqpy containing complex N886 [32].

3.5. Fe(II)-Based Complexes versus Ru(II)-Based Complexes. Benefiting from the introduction of different polypyridyl ancillary ligands, the performance of $\mathrm{Ru}(\mathrm{II})$-based complexes has been improved in some respects. For example, when going from dcbpy containing N3 to tctpy containing black dye, the spectral response range is highly extended and thus the efficiency of DSSCs is enhanced [34]. How do these ligands affect the performance of $\mathrm{Fe}$ (II)-based complexes and to what extent can it be confirmed by comparing these complexes with different polypyridyl ancillary ligands?. The key factors for confirmation include energy levels, absorption bands, and oscillator strengths. The energy levels of a sensitizer would determine the electron transfer processes which have great influence on the performance of the DSSCs [35]. As shown in Figure 3, 1, 4, and 6 provide suitable controls of the energetic and redox properties, in which the energy levels of the HOMO and LUMO match well with the redox potential of $I^{-} / I_{3}^{-}$and the conduction band of $\mathrm{TiO}_{2}$. The HOMO-LUMO gap is in sequence of $4(2.43 \mathrm{eV})$ $<\mathbf{6}(2.50 \mathrm{eV})<\mathbf{1}(2.73 \mathrm{eV})$, that is, the HOMO-LUMO gap decreases by 0.30 and $0.23 \mathrm{eV}$ when going from 1 to 4 and 6. It means that 4 and 6 have values of HOMOLUMO gap much closer to that of $\mathrm{N} 3$ with respect to the complex 1. In addition, as seen from Table 3, the lowest vertical excitation energies are also in the sequence of 4 $(766.8 \mathrm{~nm})<\mathbf{6}(724.5 \mathrm{~nm})<\mathbf{1}(633.5 \mathrm{~nm})$, corresponding to the sequence of the HOMO-LUMO gaps. Both facts indicate that the absorption bands are tuned to longer wavelengths when going from $\mathbf{1}$ to $\mathbf{4}$ and $\mathbf{6}$, thus enhancing its spectral response to the near-infrared light. 
TABLE 4: Selected absorption spectral properties of Fe(II)-based complexes (1, 4, and 6) and Ru(II)-based complexes (N3, black dye, and N886) in different organic solvents ${ }^{\mathrm{a}, \mathrm{b}}$.

\begin{tabular}{|c|c|c|c|}
\hline Complexes & $\lambda_{\max }(\mathrm{nm})$ & $f$ & Solution \\
\hline \multicolumn{4}{|c|}{ Fe(II)-based complexes } \\
\hline 1 & 571 & 0.87 & $\mathrm{CH}_{3} \mathrm{CN}$ \\
\hline 4 & 704 & 0.36 & $\mathrm{CH}_{3} \mathrm{CN}$ \\
\hline 6 & 699 & 0.31 & $\mathrm{CH}_{3} \mathrm{CN}$ \\
\hline \multicolumn{4}{|c|}{$\mathrm{Ru}(\mathrm{II})$-based complexes } \\
\hline N3 & 534 & 1.42 & $\mathrm{C}_{2} \mathrm{H}_{5} \mathrm{OH}$ \\
\hline \multirow{2}{*}{ Black dye } & 605 & 0.75 & $\mathrm{C}_{2} \mathrm{H}_{5} \mathrm{OH}$ \\
\hline & 611 & 0.73 & $\mathrm{CH}_{3} \mathrm{CN}$ \\
\hline N886 & 637 & & $\mathrm{C}_{2} \mathrm{H}_{5} \mathrm{OH}$ \\
\hline
\end{tabular}

${ }^{\mathrm{a}} \mathrm{Fe}(\mathrm{II})$-based complexes are obtained from calculations at the B3LYP/6-31G* level, while Ru(II)-based complexes are obtained from experiments.

${ }^{\mathrm{b}} \lambda_{\text {max }}$ represents maximum absorption band; $f$ represents calculated oscillator strength (arb. unit) for Fe(II)-based complexes, and $f$ represents experimental molar extinction coefficient $\left(\mathrm{M}^{-1} \mathrm{~cm}^{-1}\right)$ for $\mathrm{Ru}(\mathrm{II})$-based complexes.

On the other hand, the improving trend of $\mathrm{Fe}$ (II)-based complexes caused by using the different polypyridyl ancillary ligands can also be shown by comparing with the corresponding $\mathrm{Ru}(\mathrm{II})$-based complexes. The selected absorption spectral properties of $\mathrm{Fe}(\mathrm{II})$ - and $\mathrm{Ru}(\mathrm{II})$-based complexes are listed in Table 4. The maximum absorption bands of $\mathrm{Fe}(\mathrm{II})$ and $\mathrm{Ru}(\mathrm{II})$-based complexes show similar trend along with the introduction of different polypyridyl ancillary ligands. As shown in Table 4, the maximum absorption band of 1 centered at $571 \mathrm{~nm}$ is redshifted with respect to the corresponding values of $4(704 \mathrm{~nm})$ and $\mathbf{6}(699 \mathrm{~nm})$, in good agreement with the alterations from N3 $(534 \mathrm{~nm})$ to black dye $(605 \mathrm{~nm})$ and $\mathbf{N 8 8 6}(637 \mathrm{~nm})$. Furthermore, the relative oscillator strength of the maximum absorption band, $f_{4} / f_{1}$, is calculated to be 2.42 at the B $3 \mathrm{LYP} / 6-31 \mathrm{G}^{*}$ level. This value is in line with the experimental value of 1.90 obtained by comparing the molar absorption coefficient of $\mathrm{N} 3$ at $534 \mathrm{~nm}\left(1.42 \times 10^{4} \mathrm{M}^{-1} \mathrm{~cm}^{-1}\right)$ [8] with that of black dye at $605 \mathrm{~nm}\left(0.748 \times 10^{4} \mathrm{M}^{-1} \mathrm{~cm}^{-1}\right)$ [34]. This means that the $\mathrm{Fe}(\mathrm{II})-$ and $\mathrm{Ru}(\mathrm{II})-$ based complexes show similar relation between the structural optimizations and the spectral properties. At present, although the efficiencies using $\mathrm{Fe}$ (II)-based complexes are not comparable with those using the $\mathrm{Ru}(\mathrm{II})$ sensitizers, the greater abundance of $\mathrm{Fe}$ can offer considerable opportunities for reduction in cost. Considering that $\mathrm{Fe}(\mathrm{II})$-based complexes exhibit optical properties and trend similar to $\mathrm{Ru}(\mathrm{II})$ sensitizers and still do not undergo the barrage of investigations, it can be envisaged that $\mathrm{Fe}(\mathrm{II})$-based complexes would be competent sensitizers for DSSCs.

\section{Conclusions}

We have performed DFT/TD-DFT calculations to investigate the molecular geometries, electronic structures, and spectral characteristics of $\mathrm{Fe}(\mathrm{II})$-based complexes in both the gas phase and $\mathrm{MeCN}$ solution. The good agreement between the calculated results with the experimental observations ensures the reliability of the chosen theoretical methods. Our results show that the first three HOMOs originate from the combination of $\mathrm{Fe} 3 \mathrm{~d}$ orbitals with the $2 \mathrm{p}$ orbital and lone pairs of the thiocyanate ligands, while the first four LUMOs are composed of the antibonding combinations of the $\mathrm{C}$ and $\mathrm{N} 2 \mathrm{p}$ orbitals. The protonated/deprotonation effect is slight, while the isomerization effect and the solvent effect have great influence on the spectra characteristics of Fe(II)based complexes. The spectra show ligand-to-ligand charge transfer (LLCT) character at shorter wavelength region, whereas the spectra display multitransition characters of $\mathrm{Fe} \rightarrow$ polypyridine metal-to-ligand CT (MLCT) and LLCT transitions at the longer wavelength of the visible region. Structural optimizations by choosing different polypyridyl ancillary ligands lead to alterations of the molecular orbital energies, oscillator strength, and spectral response range. Compared with $\mathrm{Ru}(\mathrm{II})$ sensitizers, $\mathrm{Fe}(\mathrm{II})$-based complexes show similar characteristics and improving trend of optical absorption spectra along with the introduction of different polypyridyl ancillary ligands.

\section{Acknowledgments}

This work was supported by a Grant from City University of Hong Kong (Project no. 7002657) and Centre for Applied Computing and Interactive Media (ACIM). The authors would also like to thank National Natural Science Foundation of China $(10979077,21003158)$ and the Fundamental Research Funds for the Central Universities (09CX05002A) for the financial support.

\section{References}

[1] B. O’Regan and M. Grätzel, "A low-cost, high-efficiency solar cell based on dye-sensitized colloidal $\mathrm{TiO}_{2}$ films," Nature, vol. 353, no. 6346, pp. 737-740, 1991.

[2] M. Grätzel, "Photoelectrochemical cells," Nature, vol. 414, no. 6861, pp. 338-344, 2001.

[3] M. Grätzel, "Solar cells to dye for," Nature, vol. 421, no. 6923, pp. 586-587, 2003.

[4] G. Boschloo and A. Hagfeldt, "Characteristics of the iodide/triiodide redox mediator in dye-sensitized solar cells," 
Accounts of Chemical Research, vol. 42, no. 11, pp. 1819-18, 2009.

[5] M. Grätzel, "Recent advances in sensitized mesoscopic solar cells," Accounts of Chemical Research, vol. 42, no. 11, pp. 17881798, 2009.

[6] A. Hagfeldt, G. Boschloo, L. Sun, L. Kloo, and H. Pettersson, "Dye-sensitized solar cells," Chemical Reviews, vol. 110, no. 11, pp. 6595-6663, 2010.

[7] P. P. Lainé, S. Campagna, and F. Loiseau, "Conformationally gated photoinduced processes within photosensitizer-acceptor dyads based on ruthenium(II) and osmium(II) polypyridyl complexes with an appended pyridinium group," Coordination Chemistry Reviews, vol. 252, no. 23-24, pp. 2552-2571, 2008.

[8] M. K. Nazeeruddin, A. Kay, I. Rodicio, R. Humphry-Baker, E. Müller, and P. Liska, "Conversion of light to electricity by cis- $\mathrm{X}_{2}$ bis (2,2'-bipyridyl-4,4'-dicarboxylate)ruthenium(II) charge-transfer sensitizers $\left(\mathrm{X}=\mathrm{Cl}^{-}, \mathrm{Br}^{-}, \mathrm{I}^{-}, \mathrm{CN}^{-}\right.$, and $\left.\mathrm{SCN}^{-}\right)$ on nanocrystalline $\mathrm{TiO}_{2}$ electrodes," Journal of the American Chemical Society, vol. 115, no. 14, pp. 6382-6390, 1993.

[9] M. K. Nazeeruddin, F. De Angelis, S. Fantacci et al., "Combined experimental and DFT-TDDFT computational study of photoelectrochemical cell ruthenium sensitizers," Journal of the American Chemical Society, vol. 127, no. 48, pp. 1683516847, 2005.

[10] Q. J. Yu, Y. H. Wang, Z. Yi et al., "High-efficiency dyesensitized solar cells: The influence of lithium ions on exciton dissociation, charge recombination, and surface states," ACS Nano, vol. 4, no. 10, pp. 6032-6038, 2010.

[11] S. Dick and B. A. Gregg, "Crystal structure of tris(2,2'-bipyridine)iron(II) bis(hexafluorophosphate), $\left(\mathrm{C}_{10} \mathrm{H}_{8} \mathrm{~N}_{2}\right)_{3} \mathrm{Fe}\left(\mathrm{PF}_{6}\right)_{2}$," New Crystal Structures, vol. 213, no. 2, p. 356, 1998.

[12] S. Ferrere and B. A. Gregg, "Photosensitization of $\mathrm{TiO}_{2}$ by $\left[\mathrm{Fe}^{I I}(2,2 \text { '-bipyridine-4,4'-dicarboxylic acid })_{2}(\mathrm{CN})_{2}\right]$ : Band selective electron injection from ultra-short-lived excited states," Journal of the American Chemical Society, vol. 120, no. 4, pp. 843-844, 1998.

[13] L. M. Lawson Daku, A. Vargas, A. Hauser, A. Fouqueau, and M. E. Casida, "Assessment of density functionals for the high-spin/low-spin energy difference in the low-spin iron(II) tris(2,2'-bipyridine) complex," ChemPhysChem, vol. 6, no. 7, pp. 1393-1410, 2005.

[14] S. Ferrere, "New photosensitizers based upon $\left[\mathrm{Fe}(\mathrm{L})_{2}(\mathrm{CN})_{2}\right]$ and $\left[\mathrm{Fe}(\mathrm{L})_{3}\right](\mathrm{L}=$ substituted 2,2'-bipyridine): Yields for the photosensitization of $\mathrm{TiO}_{2}$ and effects on the band selectivity," Chemistry of Materials, vol. 12, no. 4, pp. 1083-1089, 2000.

[15] S. Ferrere, "New photosensitizers based upon $\left[\mathrm{Fe}^{I I}(\mathrm{~L})_{2}(\mathrm{CN})_{2}\right]$ and $\left[\mathrm{Fe}^{I I} \mathrm{~L}_{3}\right]$, where $\mathrm{L}$ is substituted 2,2'-bipyridine," Inorganica Chimica Acta, vol. 329, no. 1, pp. 79-92, 2002.

[16] F. De Angelis, A. Tilocca, and A. Selloni, "Time-dependent DFT study of $\left[\mathrm{Fe}(\mathrm{CN})_{6}\right]^{4-}$ sensitization of $\mathrm{TiO}_{2}$ nanoparticles," Journal of the American Chemical Society, vol. 126, no. 46, pp. 15024-15025, 2004.

[17] W. Gawelda, A. Cannizzo, V.-T. Pham, F. Van Mourik, C. Bressler, and M. Chergui, "Ultrafast nonadiabatic dynamics of $\left[\mathrm{Fe}^{I I}(\mathrm{bpy})_{3}\right]^{2+}$ in solution," Journal of the American Chemical Society, vol. 129, no. 26, pp. 8199-8206, 2007.

[18] A. Govindasamy, C. Lv, H. Tsuboi et al., "Theoretical investigation of the photophysical properties of black dye sensitizer $\left[\left(\mathrm{H}_{3}\right.\right.$-tctpy $\left.) \mathrm{M}(\mathrm{NCS})_{3}\right](\mathrm{M}=\mathrm{Fe}, \mathrm{Ru}, \mathrm{Os})$ in dye sensitized solar cells," Japanese Journal of Applied Physics, vol. 46, no. 4 B, pp. 2655-2660, 2007.

[19] B. D. Alexander, T. J. Dines, and R. W. Longhurst, "DFT calculations of the structures and vibrational spectra of the $\left[\mathrm{Fe}(\mathrm{bpy})_{3}\right]^{2+}$ and $\left[\mathrm{Ru}(\mathrm{bpy})_{3}\right]^{2+}$ complexes," Chemical Physics, vol. 352, no. 1-3, pp. 19-27, 2008.

[20] P. V. Bernhardt, G. K. Boschloo, F. Bozoglian, A. Hagfeldt, M. Martínez, and B. Sienra, "Tailoring mixed-valence $\mathrm{Co}^{I I I} / \mathrm{Fe}^{I I}$ complexes for their potential use as sensitizers in dye sensitized solar cells," New Journal of Chemistry, vol. 32, no. 43, pp. 705711, 2008.

[21] M. J. Frisch, G. W. Trucks, H. B. Schlegel et al., Gaussian 09, Revision A.1, Gaussian, Wallingford, Conn, USA, 2009.

[22] S. Chiodo, N. Russo, and E. Sicilia, "Newly developed basis sets for density functional calculations," Journal of Computational Chemistry, vol. 26, no. 2, pp. 175-183, 2005.

[23] D. Andrae, U. Häußermann, M. Dolg, H. Stoll, and H. Preuß, "Energy-adjusted ab initio pseudopotentials for the second and third row transition elements," Theoretica Chimica Acta, vol. 77, no. 2, pp. 123-141, 1990.

[24] X. Lu, S. Wei, C. -M. Lawrence Wu, W. Guo, and L. Zhao, "Theoretical characterization of ruthenium complexes containing functionalized bithiophene ligands for dye-sensitized solar cells," Journal of Organometallic Chemistry, vol. 696, no. 8, pp. 1632-1639, 2011.

[25] R. E. Stratmann, G. E. Scuseria, and M. J. Frisch, "An efficient implementation of time-dependent density-functional theory for the calculation of excitation energies of large molecules," Journal of Chemical Physics, vol. 109, no. 19, pp. 8218-8224, 1998.

[26] G. Scalmani, M. J. Frisch, B. Mennucci, J. Tomasi, R. Cammi, and V. Barone, "Geometries and properties of excited states in the gas phase and in solution: theory and application of a timedependent density functional theory polarizable continuum model," Journal of Chemical Physics, vol. 124, no. 9, Article ID 094107, pp. 1-15, 2006.

[27] M. Cossi and V. Barone, "Time-dependent density functional theory for molecules in liquid solutions," Journal of Chemical Physics, vol. 115, no. 10, pp. 4708-4717, 2001.

[28] S. Miertš, E. Scrocco, and J. Tomasi, "Electrostatic interaction of a solute with a continuum. A direct utilizaion of $A B$ initio molecular potentials for the prevision of solvent effects," Chemical Physics, vol. 55, no. 1, pp. 117-129, 1981.

[29] M. Cossi, V. Barone, R. Cammi, and J. Tomasi, "Ab initio study of solvated molecules: a new implementation of the polarizable continuum model," Chemical Physics Letters, vol. 255, no. 4-6, pp. 327-335, 1996.

[30] V. Barone and M. Cossi, "Quantum calculation of molecular energies and energy gradients in solution by a conductor solvent model," Journal of Physical Chemistry A, vol. 102, no. 11, pp. 1995-2001, 1998.

[31] V. Barone, M. Cossi, and J. Tomasi, "A new definition of cavities for the computation of solvation free energies by the polarizable continuum model," Journal of Chemical Physics, vol. 107, no. 8, pp. 3210-3221, 1997.

[32] C. Barolo, M. K. Nazeeruddin, S. Fantacci et al., "Synthesis, characterization, and DFT-TDDFT computational study of a ruthenium complex containing a functionalized tetradentate ligand," Inorganic Chemistry, vol. 44, no. 20, pp. 6852-6864, 2006.

[33] S. Fantacci, F. De Angelis, and A. Selloni, "Absorption spectrum and solvatochromism of the $\left[\mathrm{Ru}\left(4,4^{\prime}-\mathrm{COOH}-2,2^{\prime \prime}\right.\right.$ bpy $)_{2}(\mathrm{NCS})_{2}$ ] molecular dye by time dependent density 
functional theory," Journal of the American Chemical Society, vol. 125, no. 14, pp. 4381-4387, 2003.

[34] M. K. Nazeeruddin, P. Péchy, T. Renouard et al., "Engineering of efficient panchromatic sensitizers for nanocrystalline $\mathrm{TiO}_{2}$ based solar cells," Journal of the American Chemical Society, vol. 123, no. 8, pp. 1613-1624, 2001.

[35] R. Argazzi, N. Y. Murakami Iha, H. Zabri, F. Odobel, and C. A. Bignozzi, "Design of molecular dyes for application in photoelectrochemical and electrochromic devices based on nanocrystalline metal oxide semiconductors," Coordination Chemistry Reviews, vol. 248, no. 13-14, pp. 1299-1316, 2004. 


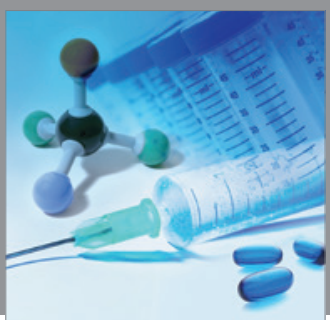

International Journal of

Medicinal Chemistry

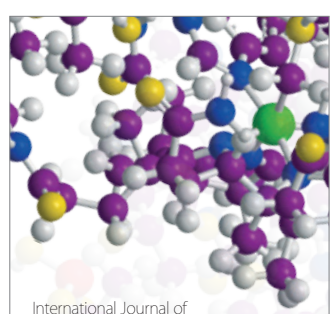

Carbohydrate Chemistry

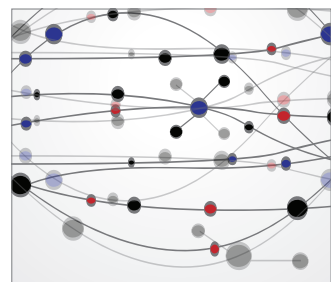

The Scientific World Journal
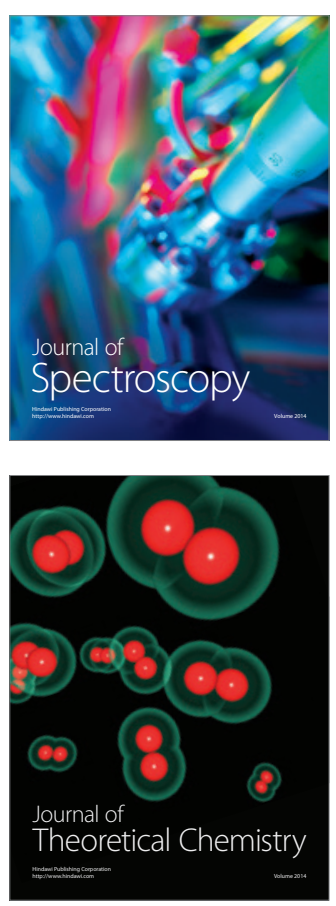
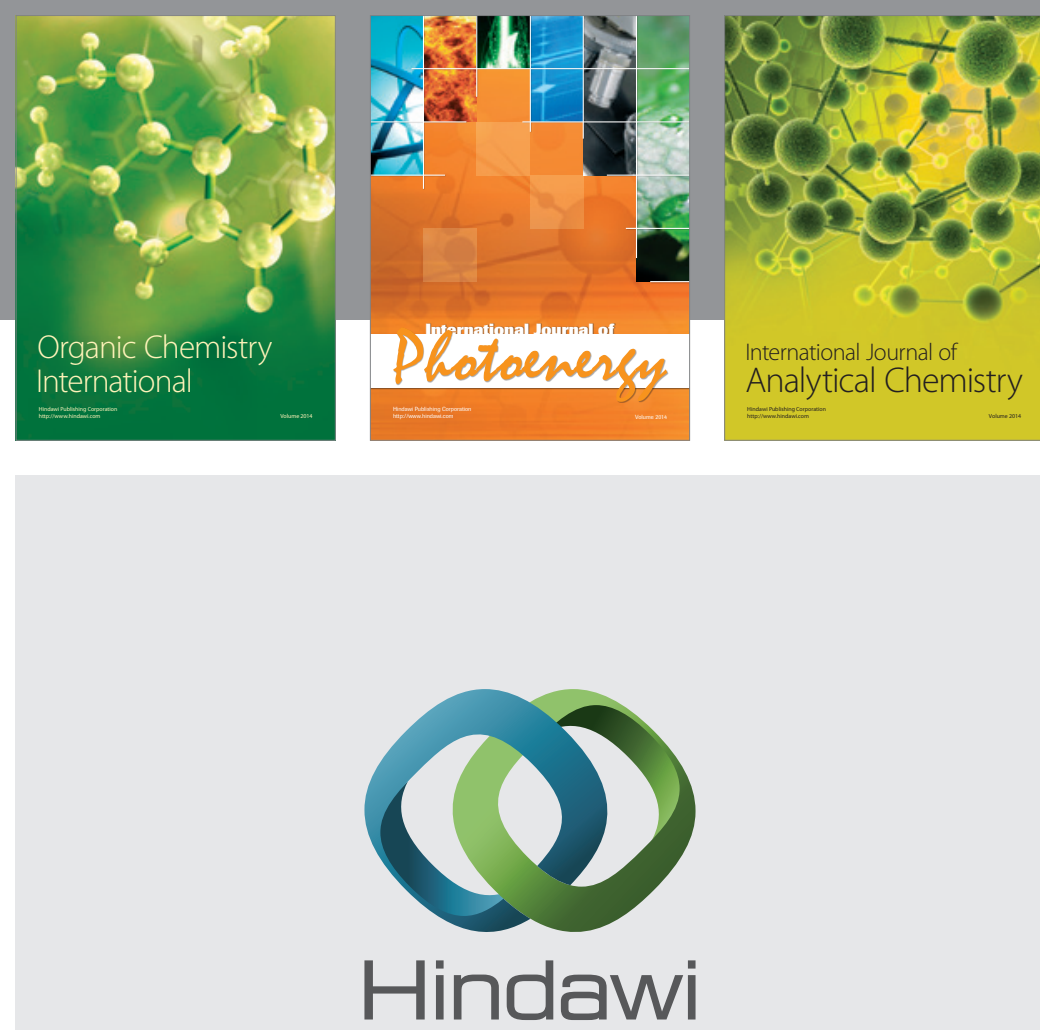

Submit your manuscripts at

http://www.hindawi.com
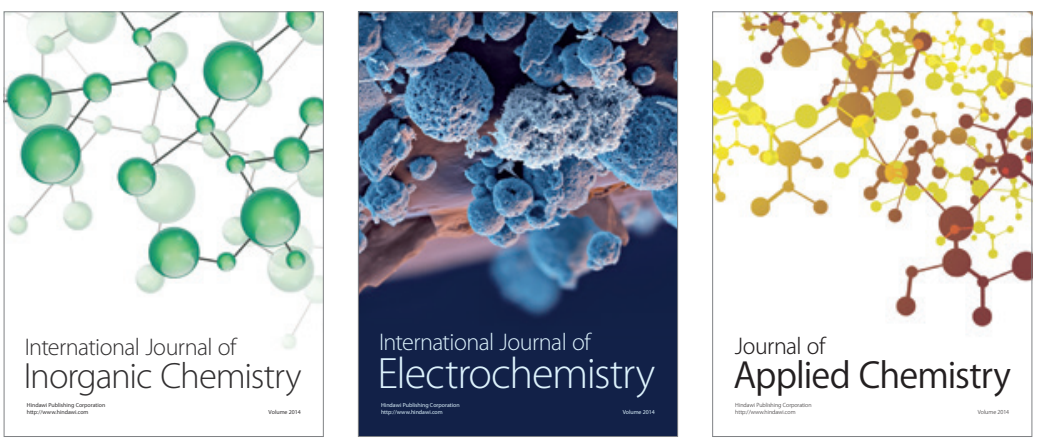

Journal of

Applied Chemistry
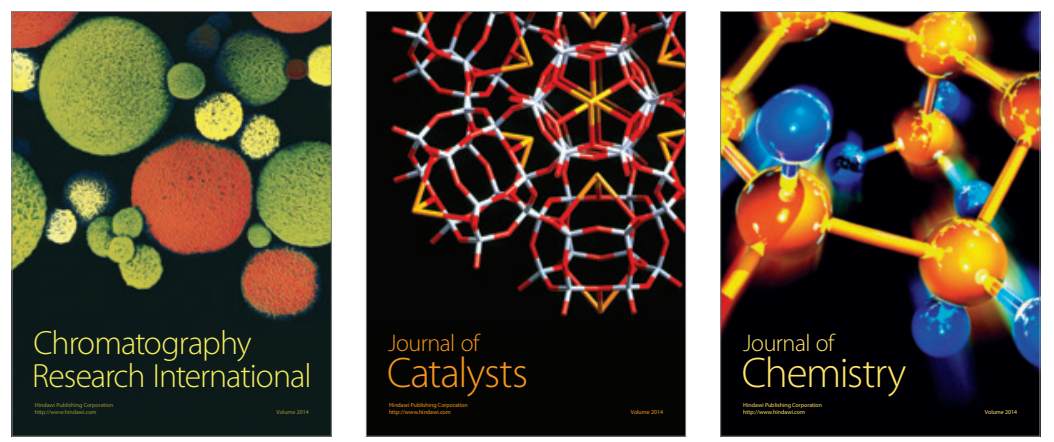
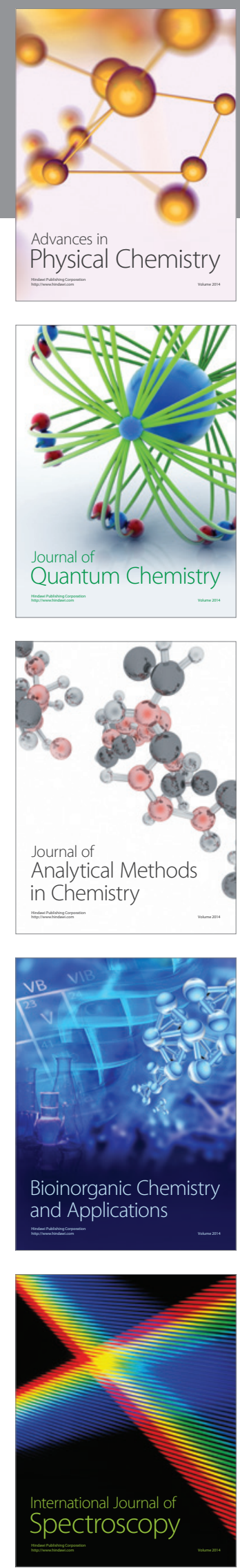